ANNALES

UNIVERSITATIS MARIAE CURIE-SKŁODOWSKA

LUBLIN - POLONIA

VOL. LXX, 1

SECTIO AA

2015

\title{
Changes in surface properties of polymethylmethacrylate (PMMA) treated with air plasma
}

Diana Rymuszka, Konrad Terpiłowski, Lucyna Hołysz and Emil Chibowski

Department Interfacial Phenomena, Faculty of Chemistry, Maria Curie-Sklodowska University, 20-031 Lublin, Poland

\section{INTRODUCTION}

Polymers because of their unique properties find an interesting application in many fields of science, technology and everyday life. Unfortunately, often polymers directly after their synthesis do not possess needed properties and therefore they have to be modified using suitable method leading to improvement of physicochemical properties of given polymer, e.g. polarity increment, surface free energy increase or build-in appropriate functional groups on the surface. Generally, improvement in hydrophilic-hydrophobic character of the surface.

The hydrophilic-hydrophobic properties of solids can be modified in several different ways, among others plasma surface treatment has become a very popular means [1-5]. This technique provides an alternative to traditional methods of surface modification like wet chemical cleaning, etching, cross-linking and functionalization. By using reactive gases in the plasma like $\mathrm{O}_{2}, \mathrm{Ar}$ or $\mathrm{CO}_{2}$ the surface becomes more hydrophilic on which new groups are formed which can interact specifically with other groups $[6,7]$. Plasma technique treatment is fast, clean and ecological method. Furthermore, it leads to obtaining the resulting material with different surface properties from the original 
polymer. Usually, in result the surface free energy of the modified by plasma surface significantly increases. On the other hand, the appropriate plasma choice, duration and temperature of treatment allow for increased the surface hydrophobicity as well. The materials which are often subjected to this type of treatment are polymers because of susceptibility of their surface to plasma modification and their wide applications. Among the polymers used for plasma treatment are: polypropylene (PP), polyethylene (PE), polymethylmethacrylate (PMMA), polyetheretherketone (PEEK), polyethylene terephthalate (PET), poly(tetrafluoroethylene) (PTFE), polydimethylsiloxane (PDMS), polyvinylidene fluoride (PVDF) and polysulfone (PS) whose surface can be modified by using argon, helium, oxygen, nitrogen, air, or less often carbon dioxide plasma [8, 9].

PMMA is a typical thermoplastic material with high endurance for UV, high rigidity and combustibility and because it is widely applied in cars and airplanes industry. In biomedicine it is applied as bone cement [10], blood filters [11], plastic surgery fillers and dental extender [12]. However, PMMA application, especially in the medical areas, is very often limited due to the fact that the adhesion between its surface and deposited film is not sufficiently strong $[13,14]$. Therefore PMMA surface needs to be modified for its stronger adhesion, and enhanced biocompatibility. This can be achieved by different methods among which plasma treatment seems to be the appropriate one. KlembergSapieha et al. [15] studied the adhesion of amorphous hydrogenated silicon nitride films prepared by plasma enhanced chemical vapor deposition, considered as an optical and protective coating on PMMA and other polymers. They found that for longer time (10-30 min) of PMMA exposure of both types $\mathrm{He}$ and $\mathrm{H}_{2}$ plasma leads to removal of outer layers on the surface and formation of crosslinked surface layer (about 50-100 $\mathrm{nm}$ thick) which stabilizes mechanically the interface [15]. In everyday life PMMA is applied inter alia as shower cabins or road screens and microelectronic microchip processing [16].

It was proved that treatment of PMMA surface with $\mathrm{Ar}, \mathrm{N}_{2}, \mathrm{O}_{2}$ or air plasma causes increase in its surface free energy and hydrophilic properties [17-21]. Furthermore, it was found that atmospheric pressure plasma treatment leads to introduction on the surface new functional groups no matter of the reactive gas type used during the modification [21]. In consequence PMMA surface becomes more tractable for further reactions.

The purpose of this research was investigation of wettability changes of PMMA modified with air plasma for 25,90 and $180 \mathrm{~s}$ via contact angle 
measurements of three probe liquids. Having measured contact angles, the surface free energy of PMMA was determined applying ef two different theoretical approaches. That proposed by van Oss et al. [22-24], in which only the advancing contact angles of three used liquids are applied, and the other one suggested by Chibowski [25-28] where the hysteresis of contact angles of these liquids are used for calculations. The chemical changes on PMMA surface were also investigated by the IR spectroscopy. Moreover, the surface roughness was estimated on the basis of three dimensional images obtained from an optical profilometer.

\section{EXPERIMENTAL}

\subsection{PMMA plates preparation}

PMMA plates of $2 \times 2 \mathrm{~cm}$ size were cut off from a bigger plate. Next the plates were cleaned thoroughly with a surfactant solution (Extran MA 02 Merck) in an ultrasonic bath for $15 \mathrm{~min}$ and rinsed with deionized water. Then the PMMA plates were rinsed with $20 \%$ methanol and deionized water and were dried for $30 \mathrm{~min}$ in a vacuum dryer.

\subsection{Air plasma treatment}

Air plasma activation was performed in a low-pressure plasma system Pico from Diener Electronic, Germany. The polymer PMMA plates were placed in the vacuum chamber and the system was subjected to pressure $0.2 \mathrm{mbar}$ at gas flow rate $22 \mathrm{sccm}$ (standard cubic centimeters per minute). The plates were treated at plasma power $160 \mathrm{~V}(400 \mathrm{~V} \max )$ for 25, 90 or $180 \mathrm{~s}$ (further denoted as PT-25, PT-90, PT-180). In order to remove the gaseous products from the chamber after treatment it was purged with air for $10 \mathrm{~s}$ and then when the pressure inside the chamber has increased to atmospheric one, the chamber was opened.

\subsection{Contact angle measurements}

Digidrop GBX Contact Angle Meter (France) equipped with a videocamera system and computer software was used for the contact angle measurements by the sessile drop method. The contact angles of probe liquids were measured at $20 \pm 1^{\circ} \mathrm{C}$ in a closed chamber. The advancing contact angles of water (Milli-Q), diiodomethane (99\% Sigma-Aldrich Germany) and formamide (POCH S.A.) were measured after gently settling $6 \mathrm{~cm}^{3}$ droplets on the surface with a help of automatic deposition 
system. Then after sucking of $2 \mathrm{~cm}^{3}$ from the droplet into the syringe, the receding contact angle was measured. In this way the contact angles of three probe liquids on the PMMA plates were measured. From mean values of the measured contact angles the apparent surface free energy was calculated for each plate.

\subsection{Surface free energy determination}

The surface free energy of after air plasma treated PMMA was determined applying two different theoretical approaches: the contact angle hysteresis (CAH) model [25-28] and the Lifshitz-van der Waals/acid-base (LWAB) model [22-24].

Using CAH model the total apparent surface free energy of a solid $\gamma_{S}^{t o t}$ is calculated from contact angle hysteresis of probe liquid and its surface free energy (surface tension) $\gamma_{L}$. The contact angle hysteresis is the difference between advancing $\theta_{a}$ and receding $\theta_{r}$ contact angles [25-28]:

$$
\gamma_{S}^{t o t}=\frac{\gamma_{L}\left(1+\cos \theta_{a}\right)^{2}}{2+\cos \theta_{a}+\cos \theta_{r}}
$$

From LWAB model, proposed by van Oss et al. [22-24], a solid surface free energy is expressed as a sum of apolar Lifshitz-van der Waals component $\gamma_{S}^{L W}$ and polar Lewis acid-base component $\gamma_{S}^{A B}$ :

$$
\gamma_{S}^{t o t}=\gamma_{S}^{L W}+\gamma_{S}^{A B}=\gamma_{S}^{L W}+2\left(\gamma_{S}^{-} \gamma_{S}^{+}\right)^{2}
$$

where $\gamma_{S}^{-}$is the electron-donor and $\gamma_{S}^{+}$is the electron-acceptor complementary parameters of the energy. Then using this approach the work of adhesion $W_{A}$ solid/liquid can be expressed following:

$W_{A}=\gamma_{L}\left(1+\cos \theta_{a}\right)=2\left(\gamma_{S}^{L W} \gamma_{L}^{+L W}\right)^{2}+2\left(\gamma_{S}^{-} \gamma_{L}^{+}\right)^{2}+2\left(\gamma_{S}^{+} \gamma_{L}^{-}\right)^{2}$

Taking advancing contact angles of at least three different liquids, one apolar (diiodomethane) and two polar (water and formamide) with known their surface free energy, one may calculate first the components of surface free energy of the solid and then its total value.

\subsection{Images of the PMMA surface from the optical profilometer and ATR-IR spectra}

With the help of an optical profilometer (Contour GT, Veeco) images of one representative PMMA sample were taken and the roughness of the surfaces were analyzed. Also the ATR-IR spectra were obtained using a spectroscope (Nicolet 8700 Tchermo). 


\section{RESULTS AND DISCUSSION}

\subsection{IR and surface roughness analysis}

The ATR-IR spectra plotted in Fig. 1 show peaks of specific original PMMA functional groups. In the range of $3050-2750 \mathrm{~cm}^{-1}$ a band characteristic for $\mathrm{C}-\mathrm{H}$ stretching bond $\left(v_{\mathrm{C}-\mathrm{H}}\right)$ is observed. The multiple peaks between 1500-1400 $\mathrm{cm}^{-1}$ are interpreted as $\mathrm{CH}_{3}$ and $\mathrm{CH}_{2}$ deformation vibrations $\left(\delta_{\mathrm{CH}_{2}}, \delta_{\mathrm{CH}_{3}}\right)$. However, the biggest intensity are observed at $1720 \mathrm{~cm}^{-1}$ corresponds to the stretching vibrations $\mathrm{C}=\mathrm{O}$ $\left(v_{C=O}\right)$ and other $1200-1100 \mathrm{~cm}^{-1}$ corresponds to the stretching vibrations $\mathrm{C}-\mathrm{O}\left(v_{C-O}\right)[29,30]$. The highest intensity is characteristic for $\mathrm{C}=\mathrm{O}$ and $\mathrm{C}-\mathrm{O}$ stretching vibration and its value increase in following order: 25,90 and $180 \mathrm{~s}$. The obtained results are consistent with the results presented by Vesel et al. [31].

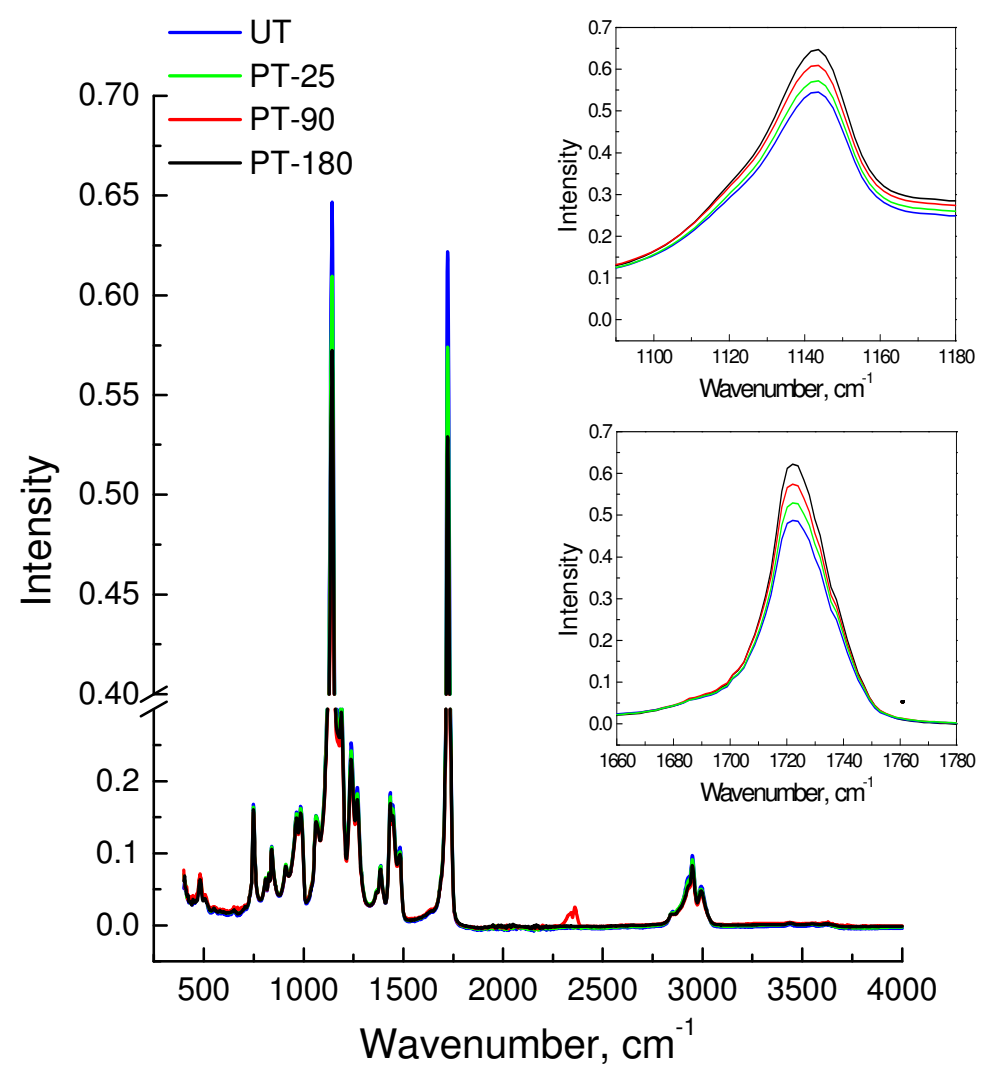

Fig. 1. IR spectra obtained for untreated (UT) and plasma treated (PT) PMMA plates for 25, 90 and $180 \mathrm{~s}$. 


\subsection{The literature PMMA XPS analysis}

Liu et al. [32] and Schultz et al. [33] found that exposition of PMMA plates to the air plasma resulted in the surface chemistry changes, which were deduced analyzing the XPS spectra. They found that the C1s peak at $285.7 \mathrm{eV}$ resulted from the quaternary carbon units of the PMMA; the third $\mathrm{C} 1 \mathrm{~s}$ peak at $286.8 \mathrm{eV}$ was due to $-\mathrm{C}-\mathrm{O}-$ species, while $\mathrm{C} 1 \mathrm{~s}$ peak at $289.1 \mathrm{eV}$ could be assigned to the carboxylic group $(\mathrm{O}-\mathrm{C}=\mathrm{O})$. The component at 532.8 $\mathrm{eV}$ could be assigned to carbonyl group $(\mathrm{C}=\mathrm{O})$, and the O1s peak at 533.8 $\mathrm{eV}$ belonged to the methyl ester group $\left(\mathrm{C}-\mathrm{O}-\mathrm{CH}_{3}\right)$. It was found that $15 \mathrm{~min}$ plasma treatment caused oxygen concentration increase on the surface by about $6 \%$ and $\mathrm{C} / \mathrm{O}$ ratio decreased by about $20 \%$ after only 2 min air plasma treatment.

\subsection{Contact angles and surface free energy analysis}

In Fig. 2 the decrease of water and formamide contact angles on PMMA depended on duration of the air plasma treatment is clearly seen. The largest decrease occurs in the case of polymer plate treated for $180 \mathrm{~s}$ (PT-180). The water contact angle decreased from $74.3^{\circ} \pm 4.2$ to $13.9^{\circ} \pm 2.4$ and that of formamide decreased from $55.6 \pm 4.4$ to $5.8 \pm 2.4$. The contact angles on original unmodified plates are in good agreement with those obtained by Liu et al. [32] and Radelczuk et al. [34].

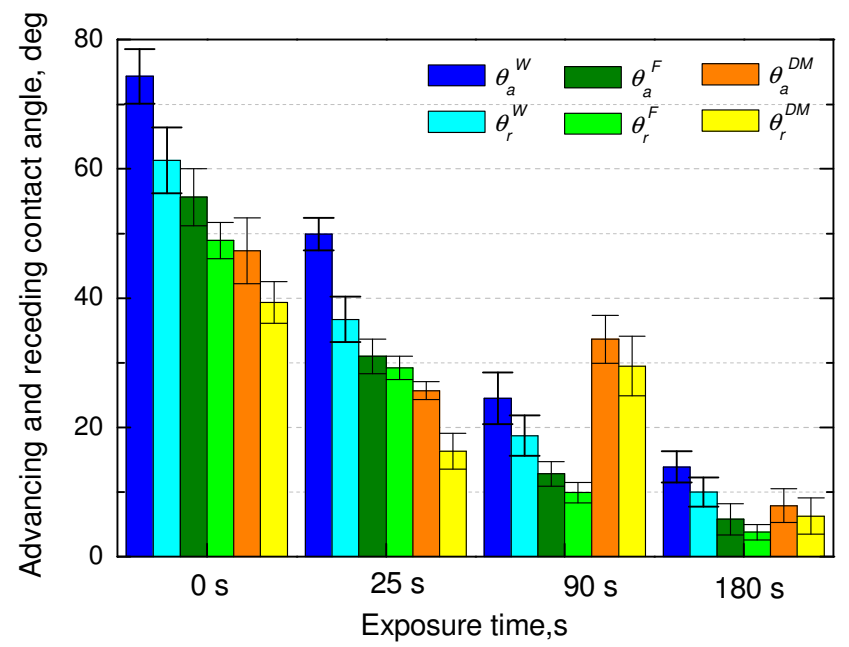

Fig. 2. Changes of advancing $\left(\theta_{a}\right)$ and receding $\left(\theta_{a}\right)$ contact angles for water $(\mathrm{W})$, formamide $(\mathrm{F})$ and diiodomethane $(\mathrm{DM})$ on untreated and plasma treated PMMA plates for different time. 
The prolongation of the plasma treatment time causes significant decrease of the probe polar liquid contact angles (i.e. water, formamide). The only one exception is observed for apolar diiodomethane where the contact angle on the PMMA plate treated with air plasma for $90 \mathrm{~s} \mathrm{(PT-90)}$ is bigger than on $25 \mathrm{~s}$ and $180 \mathrm{~s}$ treated samples, respectively (PT-25 and PT-180).

The apparent surface free energy calculated from the two approaches is very similar (Fig. 3). The surface free energy increases with prolongation of the plasma treatment time. The standard deviation of the apparent surface free energy calculated form $\mathrm{CAH}$ approach is higher than that calculated from LWAB approach.

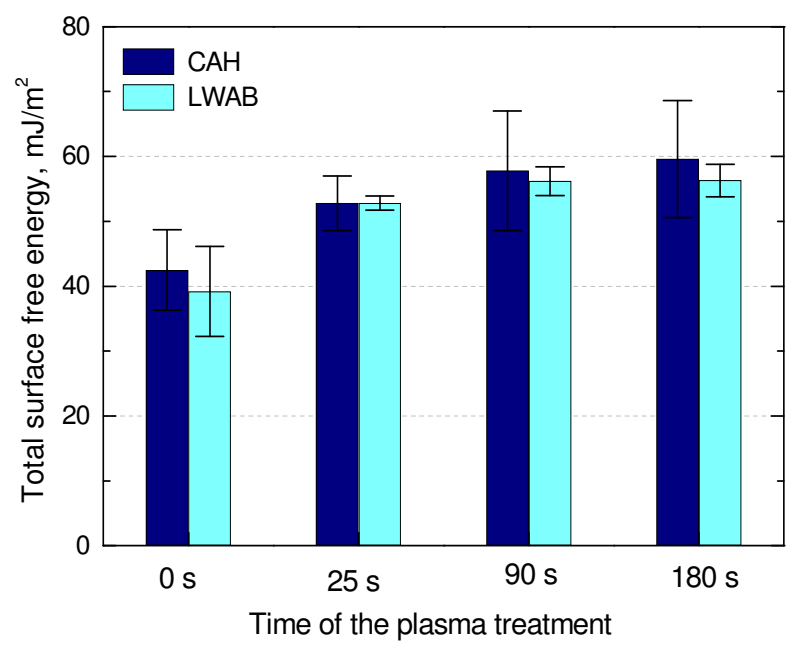

Fig. 3. Changes of PMMA surface free energy determined from $\mathrm{CAH}$ and LWAB approaches depending on the time treatment with the air plasma.

It should be mentioned that for the energy calculations from $\mathrm{CAH}$ approach, both advancing and receding contact angles are used. Therefore higher values of the apparent energy are obtained from this approach than those calculated from LWAB approach where only advancing contact angles are applied. Furthermore, the apparent surface free energy from $\mathrm{CAH}$ approach is calculated from the contact angles of each single probe liquid separately and then the averaged value is calculated. In the case of diiodomethane, which interacts by dispersive forces only, the apparent surface free energy of PMMA treated for $180 \mathrm{~s}$ calculated from $\mathrm{CAH}$ amounts $49.6 \pm 2.3 \mathrm{~mJ} / \mathrm{m}^{2}$, while it is $71.4 \pm 0.5 \mathrm{~mJ} / \mathrm{m}^{2}$ if calculated from water, and $57.8 \pm 0.2 \mathrm{~mJ} / \mathrm{m}^{2}$ if calculated from formamide contact angles. Therefore, despite that the averaged surface free energy from CAH model 
is similar to that from $\mathrm{LWAB}$, the standard deviation is bigger from $\mathrm{CAH}$. Comparison of the values obtained from both approaches gives better inside into the energetic changes taking place on the PMMA during the plasma treatment.

In Fig. 4 the components of surface free energy calculated from LWAB approach for modified and unmodified PMMA plates are presented. It can be seen that $\gamma_{S}^{+}$values are very small or negligible However, the electron-donor parameter $\gamma_{S}^{-}$increase greatly with the plasma treatment from $10 \mathrm{~mJ} / \mathrm{m}^{2}$ (original) up to $52 \mathrm{~mJ} / \mathrm{m}^{2}$ after $180 \mathrm{~s}$ plasma treated surface. Thus the $\gamma_{S}^{-}$parameter of PMMA plate treated with air plasma for $3 \mathrm{~min}$ is five times higher than for untreated PMMA surface. This clearly indicates that the electron-donor parameter is responsible for the increase in polarity of PMMA plasma treated surface. As it results from Fig. 1 the amount of oxygen atoms on PMMA increases with the air plasma exposure time.

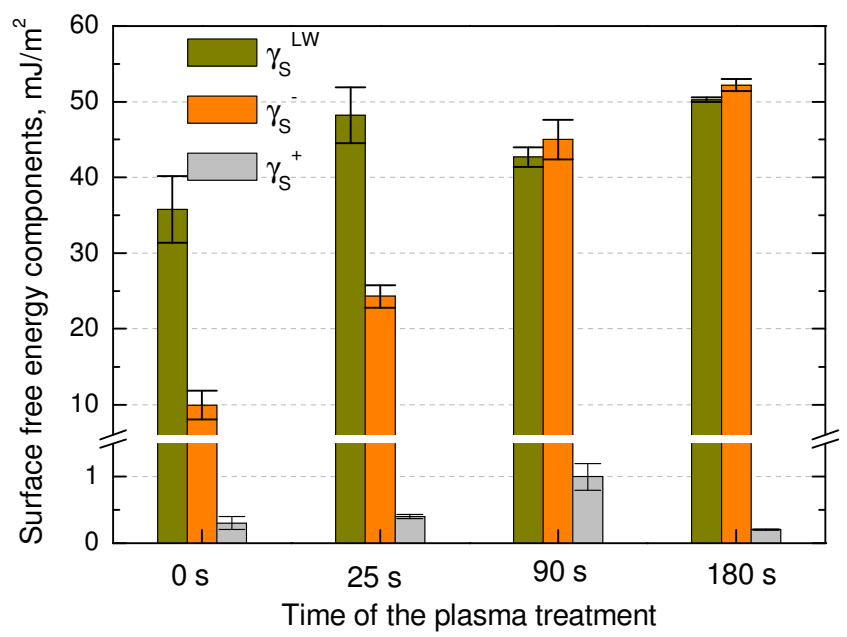

Fig. 4. The components of surface free energy determined for the untreated (UT) and plasma treated (PT) PMMA surface for 25, 90 and $180 \mathrm{s.}$

\subsection{Surface roughness analysis}

The topography images of the untreated and plasma treated PMMA surface are presented in Fig. 5. In the first column 2D images of the surface are shown and 3D images presents second column, while in the third column the roughness profiles are placed. The images were obtained using the profilometer (Contur GT) the size of scanned surfaces was $1.3 \times 0.94 \mathrm{~mm}^{2}$. The surface topography is quantified by the surface 
roughness parameters, which are: average roughness $\left(R_{a}\right)$, root-meansquared roughness $\left(R_{R M S}\right)$, and peak-to-valley difference $\left(R_{t}\right)$ (Table 1$)$.
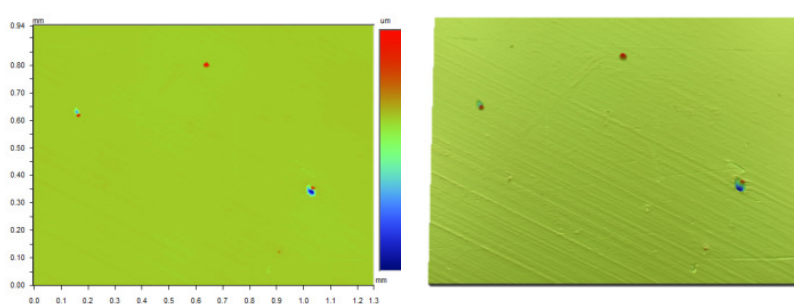

UT
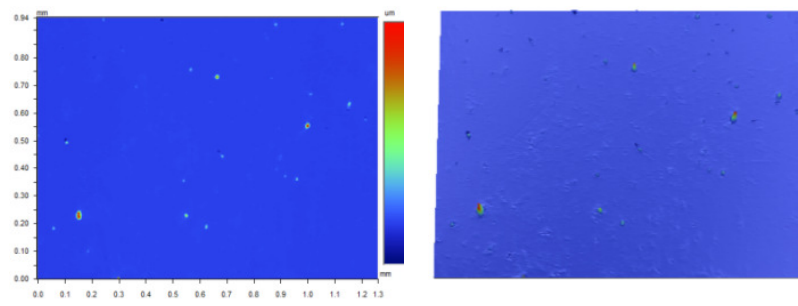

PT-25
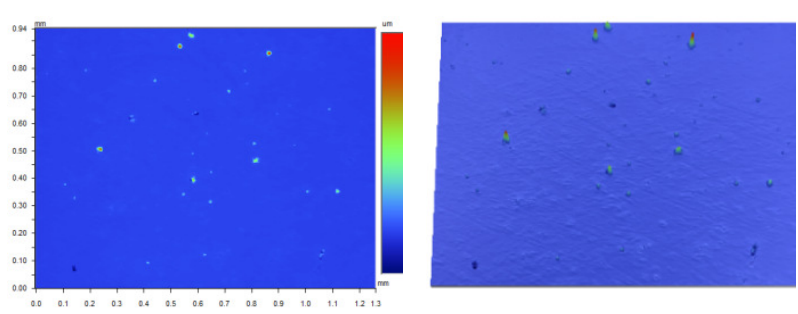

PT-90
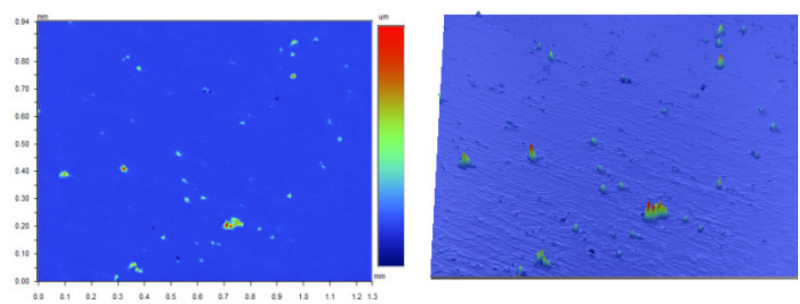

PT-180
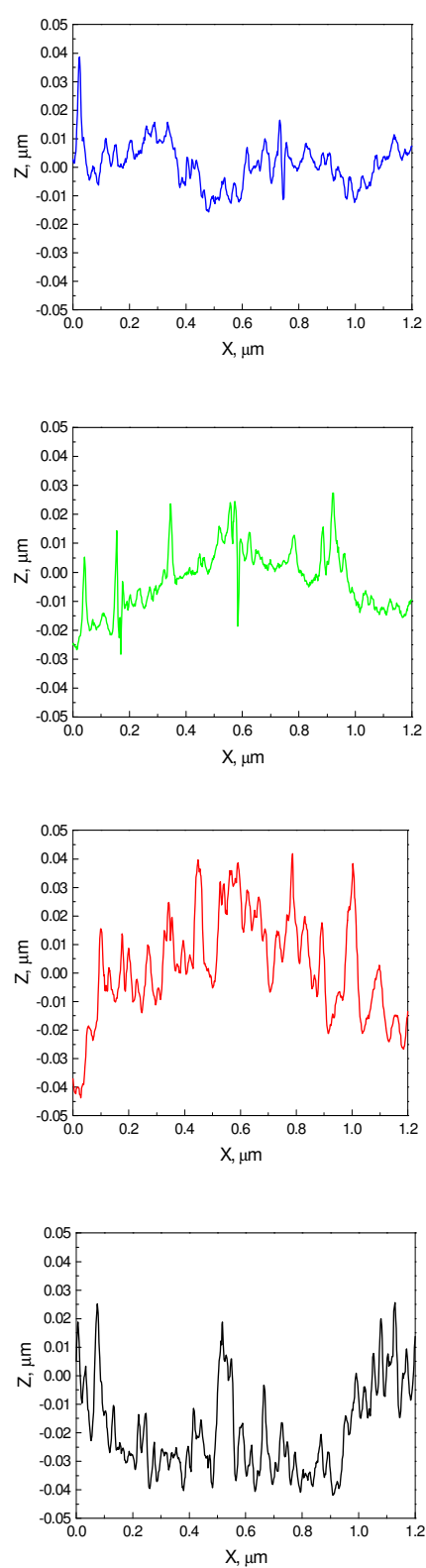

Fig. 5. 2D and 3D images of PEEK plates surface roughness for untreated (UT) and 25, 90 and 180 s treated (PT-25, PT-90, PT-180), respectively. 
Table 1. The roughness parameters: average roughness $R_{a}$, root mean square roughness $R_{R M S}$ and total height of the roughness profile $R_{t}$.

\begin{tabular}{lccc}
\hline \multicolumn{1}{c}{ Sample } & $\begin{array}{c}R_{a} \\
{[\mathrm{~nm}]}\end{array}$ & $\begin{array}{c}R_{R M S} \\
{[\mathrm{~nm}]}\end{array}$ & $\begin{array}{c}R_{t} \\
{[\mu \mathrm{m}]}\end{array}$ \\
\hline UT & 9.6 & 48.8 & 4.5 \\
PT-25 & 12.4 & 72.4 & 5.0 \\
PT-90 & 19.8 & 75.8 & 5.4 \\
PT-180 & 32.7 & 152 & 6.1 \\
\hline
\end{tabular}

The surface roughness parameters of the studied polymer surface (Table 1) show that the surface activation with plasma results in surface roughness increase. If the treatment lasted $25 \mathrm{~s}$ (PT-25) the average roughness increased from $9.6 \mathrm{~nm}$ for untreated sample to about $12.4 \mathrm{~nm}$. Longer activation with air plasma causes in further increase of the roughness. The average roughness increased to $32.7 \mathrm{~nm}$ if the plates were treated for $3 \mathrm{~min}$ (PT-130). The increasing roughness is also clearly demonstrated by $R_{R M S}$ index, which for untreated sample (UT) is 48.8 $\mathrm{nm}$ but for sample treated for $3 \mathrm{~min}$ it increase to $152 \mathrm{~nm}$. Analyzing the shape of the side profile of the surfaces it can be seen that with prolongation of the plasma activation time the surface profile becomes rougher, what also confirms the $R_{t}$ values.

\section{CONCLUSIONS}

Treatment of PMMA surface with air plasma causes increase of the amount of oxygen atoms on the surface which is confirmed by the IR spectra on which the bands characteristic for carbonyl group are present in the structure, as well as by XPS analysis found in the literature. The appearance of functional hydrophilic groups on the surface causes sharp increase in the polar interactions, especially the electron-donor parameter of apparent PMMA surface free energy. Moreover, significant increase in the surface roughness also appears on the increased hydrophilic PMMA surface. The two approaches applied to determine the apparent surface free energy show the same tendency of the energy changes, as well its similar values. As follows from the calculation, the increasing polar 
$\gamma_{S}^{-}$parameter of the surface free energy interactions is responsible for the wettability increase of the studied polymer surface.

\section{REFERENCES}

[1] H. Jung, B. Gweon, D.B. Kim and W. Choe, Plasma Process. Polym. 8, 535-41, (2011).

[2] C. Tendero, C Tixier, P. Tristant,, J. Desmaison and P. Leprince, Spectrochim. Acta B 61, 2-30, (2006).

[3] A. Fridman, A. Chirokov and A. Gutsol, J. Phys. D. Appl. Phys.38, R1-R24, (2005).

[4] O. Sakai, Y. Kishimoto and K. Tachibana, J. Phys. D. Appl. Phys. 38, 431-41, (2005).

[5] W.S. Kang, H.S. Kim and S.H. Hong, Thin. Solid. Films 518, 657882, (2010).

[6] P.K. Chu, J.Y. Chen, L.P. Wang and N. Huang, Mater. Sci. Eng. R36, 143-206, (2002).

[7] B. Gupta, J. Hilborn, C. Hollenstein, C.J.G. Plummer, R. Houriet and N. Xanthopoulos, J. Appl. Polym. Sci. 78, 1083-91, (2000).

[8] M.D. Barankin, E. Gonzalez II, S.B. Habib, L. Gao, P.C. Guschl and R.F. Hicks, Langmuir 25, 2495-2500, (2009).

[9] F. Luthon and F. Clément, Int. Conf. on Automation, Quality \& Testing, Robotics, AQTR'06, Cluj-Napoca Romania, Conference Proceeding 1-6, (2006).

[10] K.T. Chu, Y. Oshida, E.B. Hancock, M.J. Kowolik, T. Barco and S. Zunt, Hydroxyapatite/PMMA composites as bone cements, Biomed. Mater. Eng. 14, 87-105, (2004).

[11] F. Galli, S. Benedetti, U. Buoncristiani, M. Piroddi, C. Conte, F. Canestrari, E. Buoncristiani and A. Floridi, Kidney Int. 64 (2), 748-755, (2003).

[12] D. Cokeliler, S. Erkut, J. Zemek, H. Biederman and M. Mutlu, Modification of glass fibers to improve reinforcement: A plasma polymerization technique, Dent. Mater. 23, 335-342, (2007).

[13] J. Han, G. Ma and J. Ni, Mat. Sci. Eng. C 31, 1278-84, (2011).

[14] J. Dalby, L. Di Silvio and E.J. Harper, W. Bonfield, Biomat. 23, 569-76, (2002).

[15] J.E. Klemberg-Sapieha, L. Martinu, N.L.S. Yamasaki and C.W. Lantman, Thin Solid Films 476, 101-07, (2005). 
[16] M.I.J. Beale, C. Broughton, A. Pidduck, F.G.H. Smith, A.G. Brown, V.G.I. Deshmukh, T.W. Janes, S.H. Mortimer and S.J. Till, The mechanism of ion implantation passivation of PMMA for lithography with dry etch development, Microelectron. Eng. 3, 451458, (1985).

[17] S. Guruvenket, G.R.S. Iyer, L. Shestakova, P. Morgen, N.B. Larsen and G. Mohan Rao, Appl. Surf. Sci. 254, 5722-26, (2008).

[18] K. Tsougeni, P.S. Petrou, A. Tserepi, S.E. Kakabakos and E. Gogolides, Microelec. Engin. 86, 1424-42, (2009).

[19] Ch. Liu, N.-Y. Cui, S. Osbeck and H. Liang, Appl. Surf. Sci. 259, 840-46 (2012).

[20] U. Schulz, P. Munzert and N. Kaiser, Surf. Coat. Technol. 142-44, 507-11, (2001).

[21] T. Homola, J. Matousek, B. Herelova, M. Kormunda, L.Y.L. Wu and M. Cernak, Polym. Degrad. Stab. 97, 886-92, (2012).

[22] C.J. van Oss, R.J. Good and M.K. Chaudhury, J. Colloid Interf. Sci. 111, 378-90, (1986).

[23] C.J. van Oss, R.J. Good and M.K. Chaudhury, Langmuir 4, 884-91, (1988).

[24] C.J. van Oss, Colloids Surf. A 78, 1- 49, (1993).

[25] E. Chibowski, In: Contact Angle, Wettability and Adhesion, K.L. Mittal (Ed.), Ultrecht: VSP, vol. 2, 265-88, (2002).

[26] E. Chibowski and R. Perea-Carpio, Adv. Colloid Interface Sci. 98, 245-64, (2002).

[27] E. Chibowski, Adv. Colloid Interf. Sci. 103, 149-72, (2003).

[28] E. Chibowski, Adv. Colloid Interf. Sci. 113, 121-31, (2005).

[29] D. S. Bodas and S.A. Gangal, Materials Letters 59, 2903-07, (2005).

[30] A. Kondyurin and M. Bilek, Nuclear Instrum. Methods Phys. Res. B 269, 1361-69 (2011).

[31] A. Vesel and M. Mozetic, Vacuum 86, 634- 37, (2012).

[32] Ch. Liu, Nai-Yi Cui, S. Osbeck and H. Liang, Appl. Surf. Sci. 259, 840-46, (2012).

[33] U. Schulz, P. Munzert and N. Kaiser, Surf. Coat. Technol. 142-144, 507-11, (2001).

[34] H. Radelczuk, L. Hołysz and E. Chibowski, J. Adhesion Sci. Technol. 16, 1547-68, (2002). 


\section{CURRICULA VITAE}

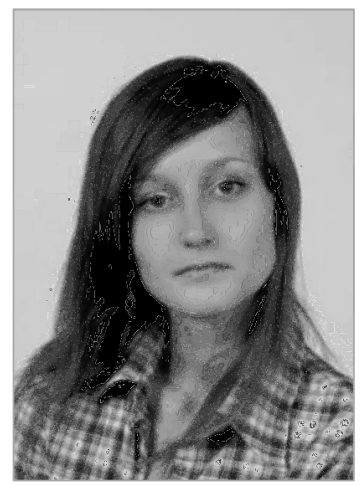

Diana Rymuszka. PhD Student of Maria CurieSktodowska University in Lublin, Poland, Department of Interfacial Phenomena, Faculty of Chemistry.

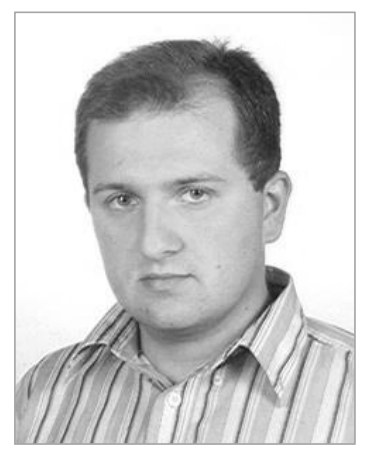

Konrad Terpitowski was born in Poland in 1979. He studied chemistry at Maria Curie Skłodowska University in Lublin and graduated in 2003. At present he is an assistant professor in the Department of Interfacial Phenomena UMCS Lublin. His research work is apparent surface free energy of solids and stability of dispersed systems.

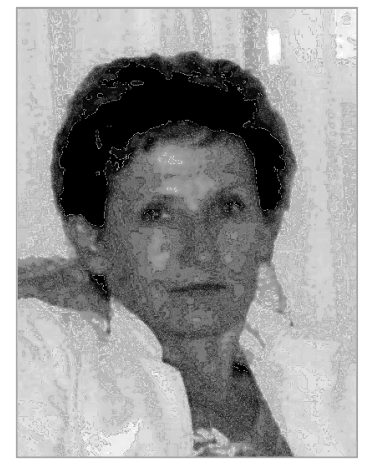

Lucyna Hołysz is a full professor and a university teacher of Physical Chemistry in the Department of Physical Chemistry-Interfacial Phenomena, Faculty of Chemistry UMCS. Her research interests is largely concentrated on interfacial phenomena and physicochemistry of the surface; physico-chemical properties of dispersed systems and their stability; the adsorption layers and the electrochemical and electrokinetic properties of solid-liquid interface; the structure and properties of the lipid layers; the preparation and characterization of superhydrophobic surfaces. She is an author and co-author of over 115 original papers in professional journals and 130 published as conference materials. 


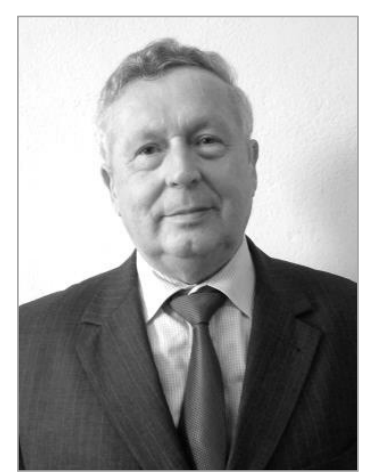

Prof. dr. hab. Emil Chibowski is employed at the Department of Interfacial Phenomena, Faculty of Chemistry UMCS in Lublin, Poland, since October 1, 1967. His fields of interest are: interfacial phenomena, electrokinetic phenomena, wetting, contact angles, surface free energy, effect of electromagnetic field on properties of dispersed systems, properties of model biological membra-nes mono- and bi-layers deposited on a solid substrate. 